\title{
EDITORIAL
}

\section{Epidemiological research in psychiatry: acting glocally}

\author{
Thiago M. Fidalgo, ${ }^{1}$ (ID Andre R. Brunoni ${ }^{2}$ (ID \\ ${ }^{1}$ Departamento de Psiquiatria, Escola Paulista de Medicina, Universidade Federal de São Paulo (UNIFESP), São Paulo, SP, Brazil. \\ ${ }^{2}$ Departamentos de Clínica Médica e Psiquiatria, Faculdade de Medicina, Universidade de São Paulo (USP), São Paulo, SP, Brazil. \\ (iD TMF https://orcid.org/0000-0003-3555-5228, iD ARB https://orcid.org/0000-0002-6310-3571
}

Epidemiology is the study of the distribution and determinants of health-related states or events. It plays a key role in public health, providing the foundations for developing strategies to control and prevent diseases, and is no less important for psychiatry and mental health. Over the past three decades, psychiatric epidemiology drew attention to the burden of mental disorders, both at the individual level (for instance, by identifying higher mortality rates among those with schizophrenia or showing an increased risk of dementia among patients with poorly controlled bipolar disorder) and at the social level for instance, by revealing that $7.4 \%$ of disability-adjusted life years (DALY) are caused by mental or behavioral disorders. ${ }^{1}$

For these reasons, this field has been considered a priority for psychiatric research., ${ }^{2,3}$ Evidence-based, evidence-driven policies are necessary worldwide, an issue that has become even more urgent among lowand middle-income countries, where limited resources demand unfailingly cost-effective investments. A proper diagnosis of mental health necessities in a specific sociocultural context is the first step toward defining priorities, followed by the identification of the most vulnerable groups that would benefit the most from preventive or clinical interventions.

Aligned with this important field and its numerous challenges, the Brazilian Journal of Psychiatry has endorsed articles covering "glocal" psychiatric epidemiological research in Brazil and Latin America. Substance userelated disorders, ${ }^{4}$ the impact of violence and early traumatic experiences on mental health outcomes, ${ }^{5}$ and health services utilization ${ }^{6}$ are some of the themes covered in this issue. Psychometric evaluation of screening instruments is also discussed in a number of articles, highlighting the importance of using proper instruments, adequately tested for specific populations, in specific cultural contexts. This in-depth look into methodological approaches for measuring and quantifying psychological distress and mental disorders has also been growing, as it provides the tools for adequate epidemiological studies. ${ }^{7}$

The number of international collaborations in the abovementioned articles is remarkable. This robust process of internationalization of Brazilian psychiatry research further raises the bar for domestic scientific output and reinforces the leading role that Brazil plays in this field. This partially explains the growing importance of the Brazilian Journal of Psychiatry in the international context. The articles published in this issue represent a wide variety of countries, such as Argentina, ${ }^{8}$ Colombia, ${ }^{5}$ and Iran. ${ }^{9}$ The high quality of the work carried out by the editorial staff and reviewers is being recognized, and the vocation of the Brazilian Journal of Psychiatry as a regional leader, championing local articles with global implications - hence the term glocal used in our title - becomes increasingly evident. The solid work developed thus far makes us optimistic for the future of the Journal and confident that great accomplishments are still to come.

\section{Disclosure}

The authors report no conflicts of interest.

\section{References}

1 Murray CJ, Vos T, Lozano R, Naghavi M, Flaxman AD, Michaud C, et al. Disability-adjusted life years (DALYs) for 291 diseases and injuries in 21 regions, 1990-2010: a systematic analysis for the Global Burden of Disease Study 2010. Lancet. 2012;380:2197-223.

2 McGrath JJ, Mortensen PB, Whiteford HA. Pragmatic psychiatric epidemiology-if you can't count it, it won't count. JAMA Psychiatry. 2018;75:111-12.

3 Weissman MM. Is psychiatric epidemiology still counting? J Clin Psychiatry. 2017;78:1314-5.

4 Massaro LT, Abdalla RR, Laranjeira R, Caetano R, Pinsky I, Madruga CS. Alcohol misuse among women in Brazil: recent trends and associations with unprotected sex, early pregnancy, and abortion. Braz J Psychiatry. 2019;41:131-7.

5 Jiménez KM, Pereira-Morales AJ, Adan A, Forero DA. Telomere length and childhood trauma in Colombians with depressive symptoms. Braz J Psychiatry. 2018 Oct 11. pii: S1516-44462018005007112. doi: 10.1590/1516-4446-2018-0027. [Epub ahead of print]

6 Ceballos GY, Paula CS, Ribeiro EL, Santos DN. Child and adolescent psychosocial care center service use profile in Brazil: 2008 to 2012. Braz J Psychiatry. 2019;41:138-47.

7 Cipresso P, Immekus JC. Back to the future of quantitative psychology and measurement: psychometrics in the twenty-first century. Front Psychol. 2017;8:2099.
Correspondence: Thiago M. Fidalgo, Departamento de Psiquiatria Universidade Federal de São Paulo (UNIFESP), Rua Major Maragliano, 241, Vila Mariana, 04017-030, São Paulo, SP, Brazil. E-mail: marquesfidalgo@yahoo.com.br
How to cite this article: Fidalgo TM, Brunoni AR. Epidemiological research in psychiatry: acting glocally. Braz J Psychiatry. 2019;41: 99-100. http://dx.doi.org/10.1590/1516-4446-2019-4102 
8 Cia AH, Stagnaro JC, Aguilar-Gaxiola S, Sustas S, Serfaty E, Nemirovsky M, et al. Twelve-month utilization rates and adequacy of treatment for mental health and substance use disorders in Argentina. Braz J Psychiatry. 2018 Nov 8:0. doi: 10.1590/1516-4446-20180036. [Epub ahead of print]
9 Shamohammadi M, Salmanian M, Mohammadi MR, Sadeghi Bahmani D, Holsboer-Trachsler E, Brand S. Prevalence of self-reported trauma in a sample of Iranian children is low and unrelated to parents' education or current employment status. Braz J Psychiatry. 2018 Dec 6:0. doi: 10.1590/1516-4446-2018-0146. [Epub ahead of print] 